\title{
DOUBLE CONVERSION UNINTERRUPTED ENERGY SYSTEM WITH RECTIFIER AND THE INVERTER INTEGRATION
}

\author{
F. M. A. Linard ${ }^{1}$, C. M. T. Cruz $^{2}$, D. S. Oliveira Júnior ${ }^{3}$, R. P. T. Bascopé ${ }^{4}$, G. A. L. Henn ${ }^{5}$. \\ Grupo de Processamento de Energia e Controle (GPEC), Departamento de Engenharia Elétrica. \\ Universidade Federal do Ceará. \\ Caixa Postal 6001, 60455-760, Campus do Pici, Fortaleza, CE, Brasil. \\ fabiola.linard@terra.com.br ${ }^{1}$, cicero@dee.ufc.br ${ }^{2}$, demercil@dee.ufc.br ${ }^{3}$, rene@dee.ufc.br ${ }^{4}$, guhenn@terra.com.br ${ }^{5}$.
}

\begin{abstract}
This paper presents the design, implementation and experimental results of a double conversion uninterrupted power supply (UPS), with integration of the rectifier and the inverter stages. The system is composed by a rectifier and an inverter, which employs a single-pole strategy for the switching modulation. The main system characteristics are: the control assembled with commercial integrated circuits, and the unified circuit of the rectifier and the inverter. Theoretical analysis, operation principle, and topology details are presented and validated through experimental results.
\end{abstract}

Keywords - Power electronics, double conversion UPS, inverter rectifier integration, reduction of components.

\section{INTRODUCTION}

Hospitals, industries, telecommunications companies, and computer centers, concern, more and more, about uninterrupted energy sources, which are internationally known as UPS, or as no-break, in Brazil, according to [1-2]. Due to the need of these sectors not to suffer surges of voltage, interruptions on the electric distribution grid, or frequency transitory oscillations, power electronics has always search for the best solution to solve these drawbacks. Thus, the usage of no-breaks is an excellent solution to keep the quality of energy to feed critical and vital loads $[1,3]$.

A UPS must protect grid-connected loads from voltage disturbances on the electric distribution grid, since the concessionaires are not always capable to assure the continuity and the quality of the supplied energy [3]. The system is composed by a rectifier, an inverter, a bank of batteries, a bypass circuit, and a galvanic isolation between the transformer input and output $[5,6]$.

The basic objective of a DC-AC converter is to transform a direct voltage source in alternated symmetrical voltage source with pre-defined amplitude and frequency. These converters, known as "inverters", can be divided into four groups, in accordance to the needed output: dc-ac voltage converters, dc-ac current converters, dc-ac current regulated converters, and phase-controlled dc-ac converters. The most common is the dc-ac voltage converter, which is the initial source of this research.
Among the existing topologies, the full-bridge singlephase voltage inverter, the half-bridge single-phase voltage inverter, and the push-pull inverter are the most used, due to their characteristics. The first one, shown in Figure 1, is more suitable for high power, high voltage applications [2, 5-7, 13, 14]. The output voltage is $\mathrm{AC}$ and behaves as a sine waveform. The input can be batteries, solar panels or any other DC voltage source. In some cases their input are filtered rectifying circuits, before entering the inversion process, as presented in [5].

This paper presents two stages employed in a basic UPS topology: the rectifier and the inverter, operating in a unique set structure, as presented in Figure 2. The developed topology was first proposed by Divan [8], though applying a distinct modulation and low capacitance for the input DC bus.

The main advantages observed in this structure are: reduced costs, as it employs a small number of components, low voltage stress across the switches, and the qualities of a single-pole PWM modulation. On the other hand, such characteristics lead to a more complex control strategy.

For inverter applications, the output voltage control and regulation is necessary. The modulation method chosen in this work was a sinusoidal PWM with filter, used for harmonic attenuation. Also, the proposed configuration has the following parameters: input voltage $220 \mathrm{~V}$, output voltage $110 \mathrm{~V}$, and nominal power $1 \mathrm{kVA}$.

\section{DESCRIPTION OF PROPOSED TOPOLOGY}

In the proposed topology, switches $\mathrm{S}_{5}$ and $\mathrm{S}_{6}$ commutate in low frequency $(60 \mathrm{~Hz})$, which, along with diodes $\mathrm{D}_{1}$ and $\mathrm{D}_{2}$, present a similar operation of a full-wave rectifier. Switches $\mathrm{S}_{3}$ and $\mathrm{S}_{4}$ are complementary to each other and operate at 20 $\mathrm{kHz}$ during the two semi-cycles of the input voltage. The proposed switching strategy reduces the stresses across the semiconductors to a level lower than one presented in [5].

For the prototype assembling, switches IFGP50B60PD1 and the rectifier bridges GBPC 3521A were used for the power stage. 


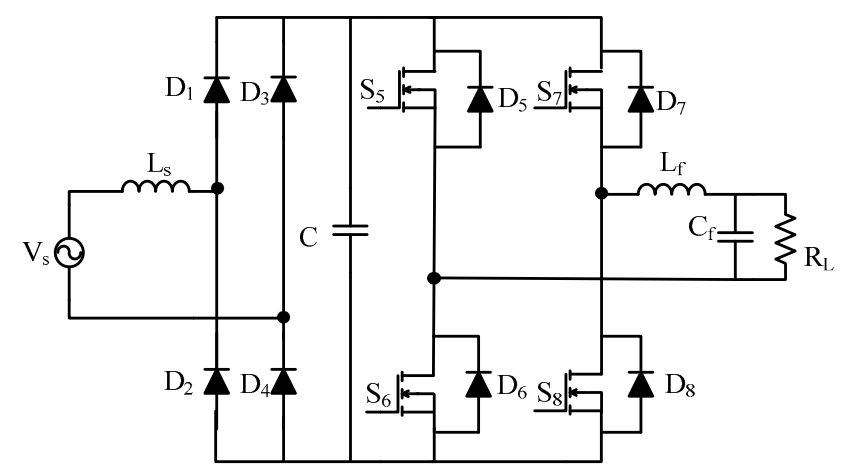

Fig. 1. Single-phase rectifier and inverter in full-bridge topology.

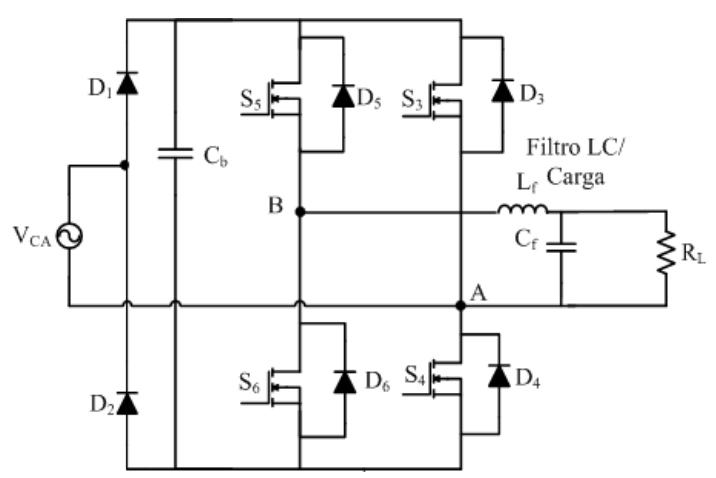

Fig. 2. Proposed topology.

\section{A. Operation Principle}

The operation stages will be described using the singlepole modulation. These stages have been divided into two semi-cycles, positive and negative, in accordance with the output voltage. For the theoretical analysis it will be considered that all elements, active and passive, are ideal, the output voltage is a pure sine wave, and the system operates in steady state.

1) Positive semi-cycle of the Output Voltage - It is divided in two intervals: on the first one, the $\mathrm{DC}$ bus voltage $\left(\mathrm{V}_{\mathrm{CC}}\right)$ is greater than the input voltage $\left(\mathrm{V}_{\mathrm{CA}}\right)$, and the second, when the input voltage is greater than the $\mathrm{DC}$ bus one.

$V_{C C}>\left|V_{C A}\right|$ :

First stage $\left[\mathbf{t}_{\mathbf{0}}-\mathbf{t}_{\mathbf{a}}\right]$ - This stage, presented on Figure 3, begins when $\mathrm{S}_{3}$ is turned-on. The circuit is fed by the $\mathrm{Cb}_{b}$ capacitor that will be discharged by the filtering inductor $L_{f}$. The voltage $\mathrm{V}_{\mathrm{AB}}$ is positive and the current through the inductor increases linearly in its negative semi-cycle. This stage ends when $\mathrm{S}_{3}$ turns-off.

Second stage $\left[\mathbf{t}_{\mathbf{a}}-\mathbf{t}_{\mathbf{b}}\right]$ - This stage is presented in Figure 4. As $\mathrm{S}_{3}$ remains blocked, the DC bus is disconnected from the circuit, $\mathrm{D}_{4}$ assumes the inductor current, and voltage $\mathrm{V}_{\mathrm{AB}}$ goes to zero. The diode $\mathrm{D}_{4}$ conducts, due to the direction of the current imposed by Lf, which remains unchanged, and continue to flow through $\mathrm{S}_{6}$. The inductor $\mathrm{Lf}_{\mathrm{f}}$ is discharged, making its current increases linearly until it is near to zero, in its negative semi-cycle. This stage finishes when the switch $\mathrm{S}_{4}$ is turned-off.

$$
V_{C C}<\left|V_{C A}\right| \text { : }
$$

Third stage $\left[\mathbf{t}_{\mathbf{b}}-\mathbf{t}_{\mathbf{c}}\right]$ - The third stage of the positive semicycle begins when the input voltage starts to be greater than the voltage on DC bus. At this moment, diode $\mathrm{D}_{1}$ starts to conduct and the DC bus capacitor will start to be charged, as well as the $\mathrm{L}_{\mathrm{f}}$ inductor. The voltage $\mathrm{V}_{\mathrm{AB}}$ is positive, as shown in Figure 5. The current flows through $\mathrm{D}_{6}$, due to the fact that the current flowing through $\mathrm{D}_{1}$ is higher than the one through $\mathrm{Lf}$, as the current in $\mathrm{D}_{1}$ is the sum of the current that flows through $\mathrm{S}_{3}$ and the one that circulates through the DC bus. This stage finishes when $\mathrm{S}_{3}$ is turned-off.

Fourth stage $\left[\mathbf{t}_{\mathbf{c}}-\mathbf{t}_{\mathbf{d}}\right]$ - This stage starts when $S_{3}$ is blocked, as presented in Figure 6 . The direction of the current polarizes $\mathrm{D}_{4}$, the voltage $\mathrm{V}_{\mathrm{AB}}$ is zero, and the current through $\mathrm{D}_{1}$ is greater than the current through the $\mathrm{Lf}_{\mathrm{f}}$ inductor, as it is the sum of the currents through $\mathrm{D}_{4}$ and $\mathrm{D}_{6}$. When the input voltage starts to be lower than the DC bus one, the inverter comes back to operation stages 1 and 2 until the output voltage goes to zero again, beginning a new cycle.

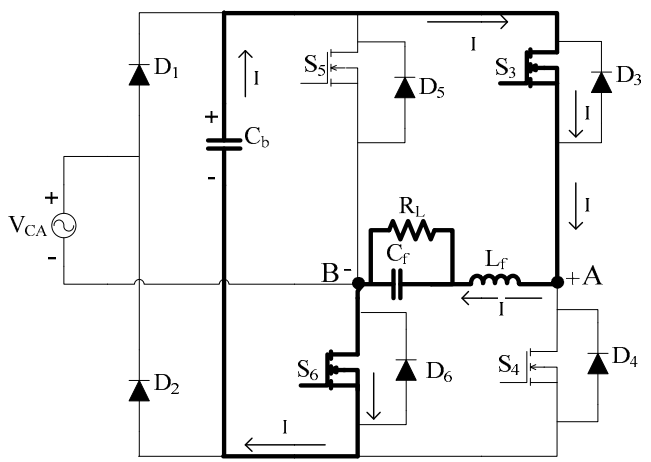

Fig. 3. First stage of the positive semi-cycle of the output voltage.

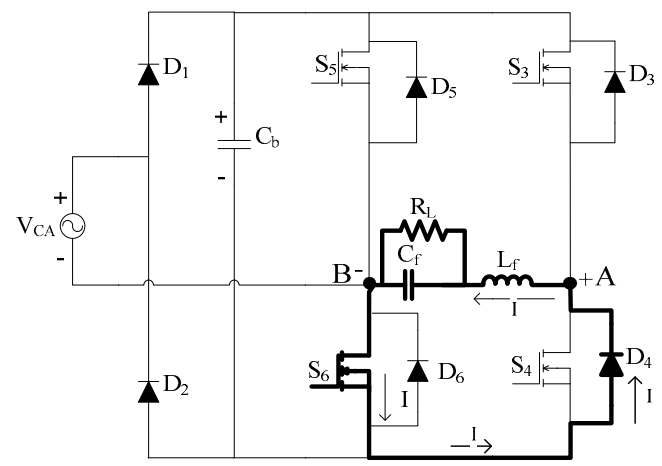

Fig. 4. Second stage of the positive semi-cycle of the output voltage.

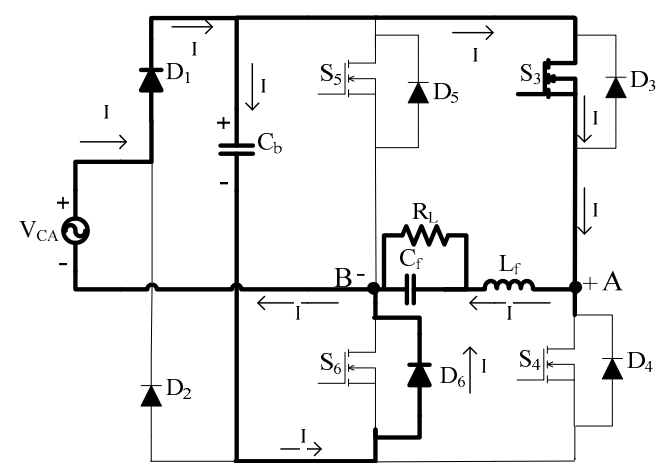

Fig. 5. Third stage of the positive semi-cycle of the output voltage. 


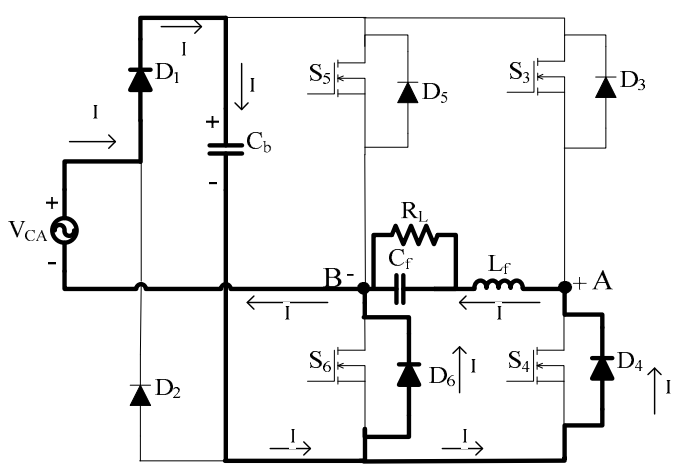

Fig. 6. Fourth stage of the positive semi-cycle of the output voltage.

2) Negative semi-cycle of the Output Voltage - It is divided in two intervals: while the slide DC bus voltage is greater than the input one, and when the input is greater than DC bus one.

$$
V_{C C}>\left|V_{C A}\right| \text { : }
$$

First stage $\left[\mathbf{t}_{\mathbf{d}}-\mathbf{t}_{\mathbf{e}}\right]-$ At instant $t_{d}, S_{4}$ and $S_{5}$ are turned-on, connecting the load and the filter LC to the DC bus, which supplies it. The voltage $\mathrm{V}_{\mathrm{AB}}$ is negative and the current through the inductor increase in its positive semi-cycle. This stage can be observed in Figure 7 and finishes when $\mathrm{S}_{4}$ is turned-off.

Second stage $\left[\mathbf{t}_{\mathbf{e}}-\mathbf{t}_{\mathbf{f}}\right]-$ During this stage, the current that flows through the $\mathrm{L} f$ inductor remains on the same direction, because $\mathrm{D}_{3}$ is conducting. The voltage $\mathrm{V}_{\mathrm{AB}}$ is zero, the current through the Lf inductor decreases, and the energy previously stored on the inductor is now delivered to the load. The second stage of operation can be seen in Figure 8 and it finishes when $\mathrm{S}_{3}$ turns-off.

$$
V_{C C}<\left|V_{C A}\right| \text { : }
$$

Third stage $\left[\mathbf{t}_{\mathbf{f}}-\mathbf{t}_{\mathbf{g}}\right]-$ During this stage, $\mathrm{D}_{2}$ and $\mathrm{S}_{4}$ are conducting. The voltage $\mathrm{V}_{\mathrm{AB}}$ becomes negative $\left(-\mathrm{V}_{\mathrm{CC}}\right)$ and the current through Lf inductor increases. Figure 9 shows this operation stage, which ends when $\mathrm{S}_{4}$ turns-off.

Fourth stage $\left[\mathbf{t}_{\mathbf{g}}-\mathbf{t}_{\mathbf{h}}\right]$ - Figure 10 presents the fourth stage, which begins when $\mathrm{S}_{4}$ turns-off, forcing $\mathrm{D}_{3}$ to conduct. The voltage $\mathrm{V}_{\mathrm{AB}}$ goes to zero and the current through the $\mathrm{Lf}_{\mathrm{f}}$ inductor decreases, delivering the previously stored energy to the load. This stage ends when S4 turns-on.

When the input voltage is lower than the DC bus voltage the inverter will operate again on stages 1 and 2 . The $D_{2}$ is blocked until the output voltage decrease to zero starting a new cycle.

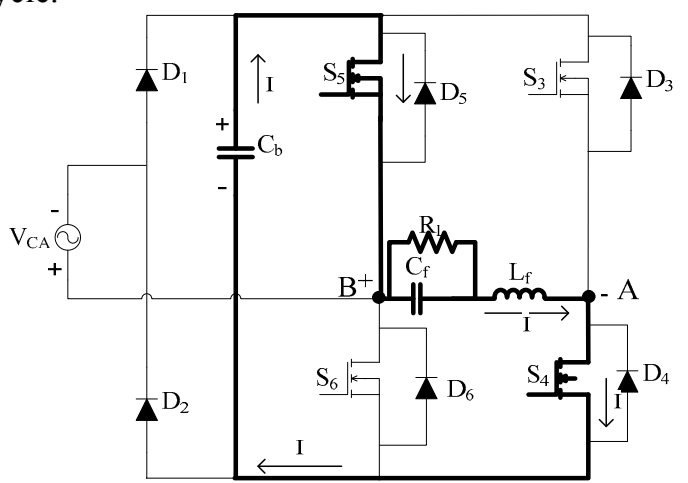

Fig. 7. First stage of the negative semi-cycle of the output voltage.

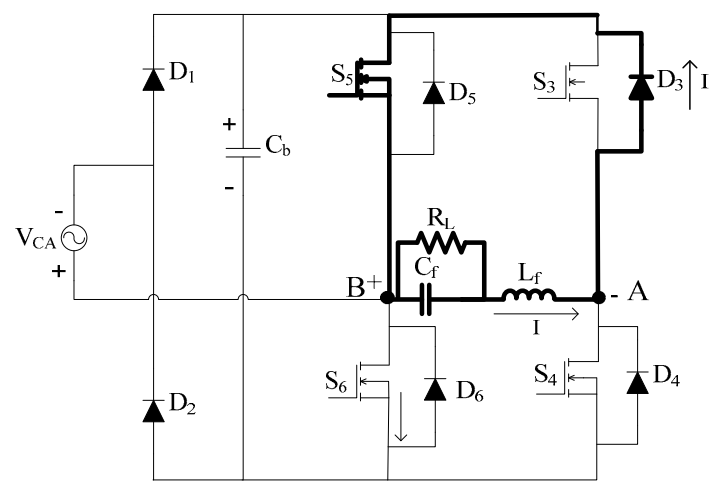

Fig. 8. Second stage of the negative semi-cycle of the output voltage.

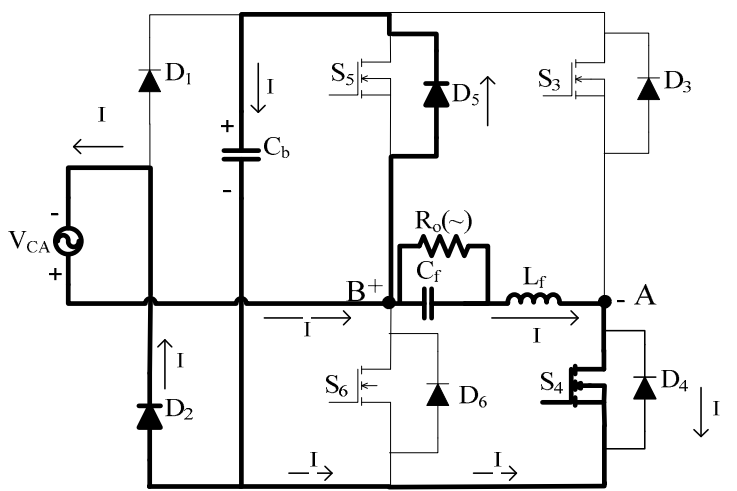

Fig. 9. Third stage of the negative semi-cycle of the output voltage.

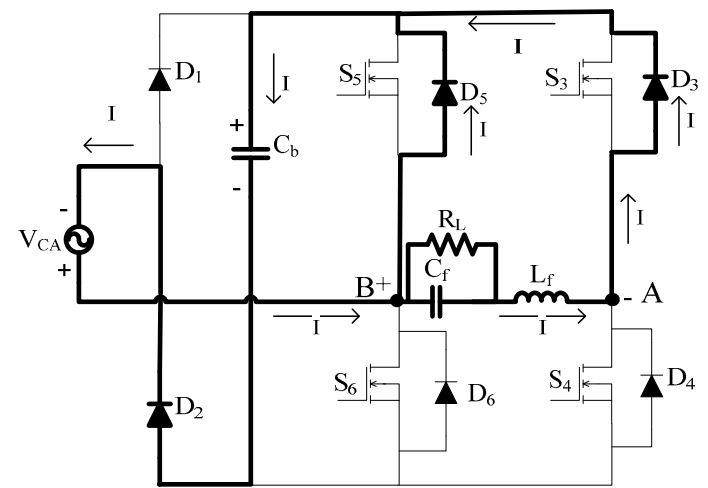

Fig. 10. Fourth stage of the negative semi-cycle of the output voltage.

\section{B. Applied Modulation}

The modulation strategy adopted to control the switches of the proposed topology, presented in Figure 2, was the three-level sinusoidal PWM with a rectified sine wave reference, in order to lower the ripple of the output voltage, in accordance with [4] and [7]. Appling the sinusoidal PWM with a rectified sine wave reference, and the modulation of just one leg of the inverter, it is possible to obtain three levels on the output voltage. $\mathrm{S}_{5}$ and $\mathrm{S}_{6}$ commutate on the frequency of the input voltage, and the other leg, formed by $\mathrm{S}_{3}$ and $\mathrm{S}_{4}$, is controlled by comparing a modulator sine wave signal with a triangular carrier.

During the positive semi-cycle of the input voltage, $\mathrm{S}_{6}$ and $\mathrm{D}_{1}$ are turned-on, while $\mathrm{S}_{5}$ and $\mathrm{D}_{2}$ are blocked, and viceversa on the negative semi-cycle. When $\mathrm{S}_{5}$ and $\mathrm{S}_{6}$ are conducting, $\mathrm{S}_{3}$ and $\mathrm{S}_{4}$ are complementarily switched in high 
frequency. In this type of modulation the output voltage presents three instantaneous values: $+\mathrm{V}_{\mathrm{CC}}$, zero or - V $\mathrm{V}_{\mathrm{CC}}$.

The proposed modulation requires a low-pass LC output filter, in order to prevent distortions on the output voltage. It must be noticed that this filter was chosen due to its characteristics of reducing reactive components, lower the output voltage ripple, and low cost, weight and volume.

The filter inductance and capacitance can be expressed by equations (1) and (2), respectively, according to $[1,17,18]$.

$$
\begin{gathered}
L_{f}=\frac{\sqrt{2} \cdot V_{o} \cdot\left(\sqrt{2} \cdot V_{i n_{p k}}-\sqrt{2} \cdot V_{o}\right)}{2 \cdot \Delta I_{L f} \cdot f_{s} \cdot V_{i n_{p k}}} \\
C_{f}=\frac{1}{L_{f} \cdot\left(\frac{2 \cdot \pi \cdot f_{s}}{10}\right)^{2}}
\end{gathered}
$$

Where:

$\mathrm{V}_{\text {in pk }}$ - Peak input voltage.

$\mathrm{V}_{\mathrm{o}} \quad$ - Output voltage.

$\Delta \mathrm{I}_{\mathrm{Lf}}$ - Current ripple through the filter inductor.

$f_{s} \quad-$ Switching frequency.

\section{Control strategy}

The control technique developed is known as voltage loop control and is widely applied on inverters. It consists of monitoring the output voltage and comparing it with a sine reference voltage. To generate the synchronized reference voltage with the input one, a microcontroller is used.

The inverter transfer function was obtained through the CCM small-signal Buck converter analysis, according to [11], and implemented as shown in Figure 11 [12].

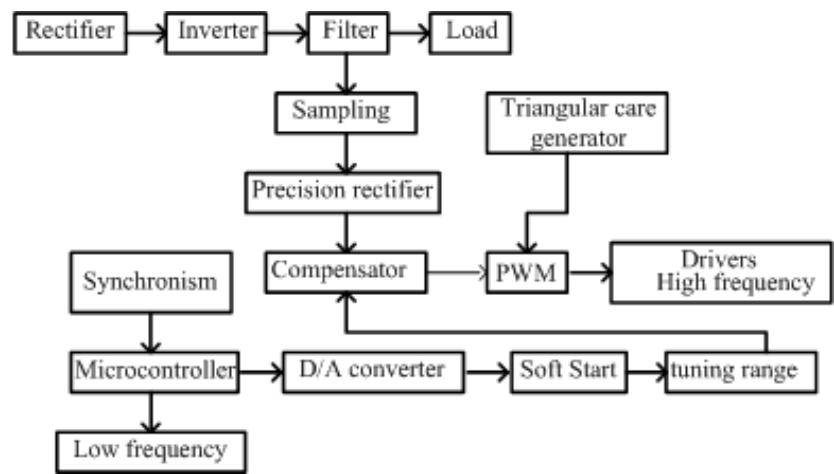

Fig. 11. Schematic diagram of the proposed control strategy.

In order to control the output voltage loop, it was chosen the PID compensator. The poles allocation criterions were adopted as follows: one pole was allocated on the origin, minimizing the static error during the permanent regime, while the other was allocated on the switching frequency in order to attenuate high frequency signals on the voltage loop.
The zeros were allocated on the natural oscillation frequency and the open loop crossing frequency (FTLAv) is adopted as four times lower than the switching frequency [11].

Adopting these criterions, the zeros and poles frequencies can be calculated: $\mathrm{f}_{\mathrm{z} 1}=\mathrm{f}_{\mathrm{z} 2}=1,659 \mathrm{kHz}, \mathrm{f}_{\mathrm{p} 1}=0 \mathrm{~Hz}$ e $\mathrm{f}_{\mathrm{p} 2}=$ $16,593 \mathrm{kHz}$.

Figure 11 presents the Bode diagram of the open loop transfer function, where can be observed the system before the compensation (dashed line), and the compensated system (solid line). The phase margin is 32 degrees.

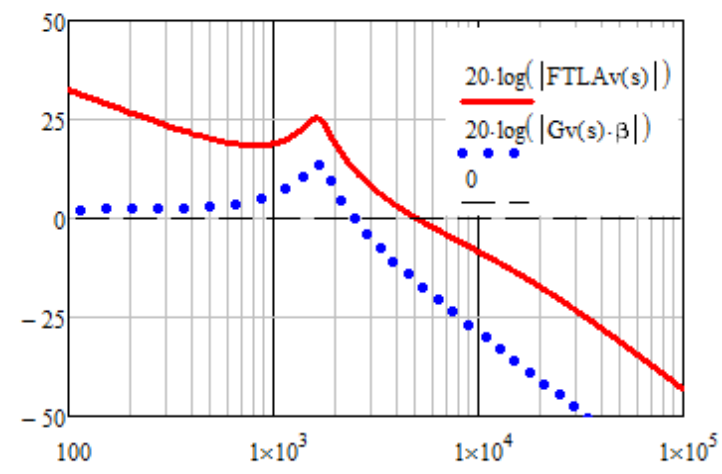

(a)

$\frac{s}{2 \cdot \pi}$

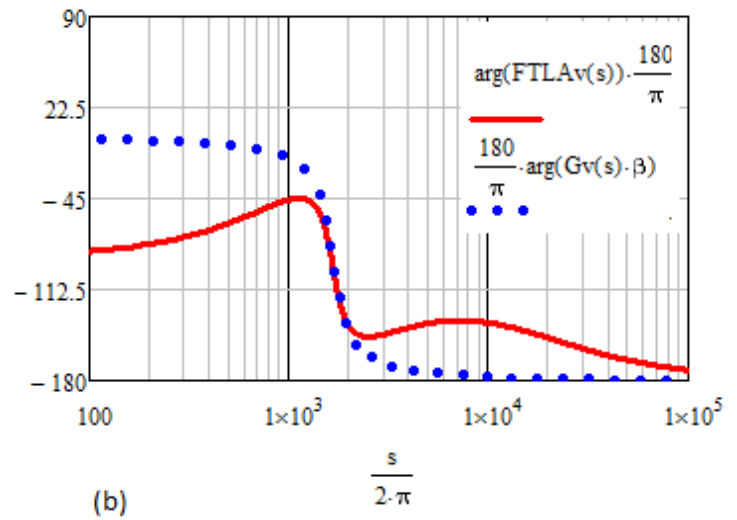

Fig. 12. Bode diagram of the open loop transfer function (a) gain, (b) phase.

\section{SWITCHING STRESS ANALISYS}

The current peak value through $\mathrm{D}_{1}$ and $\mathrm{D}_{2}$, can be expressed by equation (3) [19]:

$$
I_{D 1_{p k}}=\frac{C_{b}\left(V_{c_{p k}}-V_{c_{\min }}\right)}{t_{c}}
$$

The waveform of the instantaneous current through $\mathrm{S}_{3}$ is shown in Figure 13. The average value of this current can be approached by (4) [15].

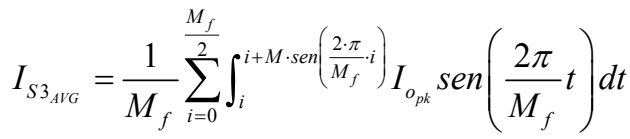

The frequency index of the inverter is the relation between the frequency of the carrier signal $\left(f_{p}\right)$ and the frequency of the modulating signal $\left(\mathrm{f}_{\mathrm{m}}\right)$. The value of the RMS current is given by (5) [15]. 


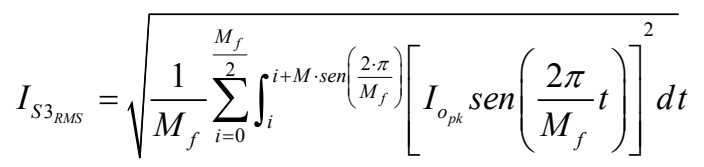

Where:

$$
\begin{array}{ll}
\mathrm{M} & \text { - Modulation index. } \\
\mathrm{M}_{\mathrm{f}} & \text { - Frequency index. } \\
\mathrm{I}_{\mathrm{o}} & \text { - Load current. } \\
\mathrm{f}_{\mathrm{m}} & \text { - Modulating wave. } \\
\mathrm{f}_{\mathrm{p}} & \text { - Carrier wave. } \\
\mathrm{I}_{\mathrm{o} \text { p }} & \text { - Load current peak. }
\end{array}
$$

Diode $\mathrm{D}_{3}$ conducts when $\mathrm{S}_{4}$ is blocked and the current through it is behaves as the waveform presented on Figure 14. The average current through $\mathrm{D}_{3}$ is equal to the average current through $\mathrm{D}_{4}$, which can be calculated as (6), based on Figure 13 [15]. The current RMS value through $\mathrm{D}_{3}$ and $\mathrm{D}_{4}$ can be expressed as (7).

$$
\begin{aligned}
I_{D 3_{A V G}} & =\frac{1}{M_{f}} \cdot \sum_{i=0}^{\frac{M_{f}}{2}} \int_{i+M \cdot \operatorname{sen}\left(\frac{2 \cdot \pi}{M_{f}} \cdot i\right)}^{i+1} I_{o_{p k}} \operatorname{sen}\left(\frac{2 \pi}{M_{f}} t\right) d t \\
I_{D 3_{\text {RUS }}} & =\sqrt{\frac{1}{M_{f}} \sum_{i=0}^{\frac{M_{f}}{2}} \int_{i+M \cdot \operatorname{sen}\left(\frac{2 \cdot \pi}{M_{f}}\right)}^{i}\left[I_{o_{p k}} \operatorname{sen}\left(\frac{2 \pi}{M_{f}} t\right)\right]^{2}} d t
\end{aligned}
$$

In order to calculate of the average and RMS current through $\mathrm{S}_{5}$ and $\mathrm{S}_{6}$, it must be considered the instant when the switches are blocked on its operation stage. Thus, the average current can be expressed by (8) [15].

$$
I_{S S_{A V G}}=\frac{1}{2 \pi}\left(\int_{0}^{t_{1} \pi} I_{o_{p k}} M \operatorname{sen}(\omega t) d \omega t+\int_{t_{c 2} \pi}^{\pi} I_{o_{p k}} M \operatorname{sen}(\omega t) d \omega t\right)(8)
$$

The RMS current through these switches can be calculated by (9) [15].

$$
I_{R M S}=\sqrt{\frac{1}{2 \pi}\left(\int_{0}^{t_{1} \pi}\left(I_{o_{p k}} M \operatorname{sen}(\omega t)\right)^{2} d \omega t+\int_{t_{c 2} \pi}^{\pi}\left(I_{o_{p k}} M \operatorname{sen}(\omega t)\right)^{2} d \omega t\right)}(9)
$$

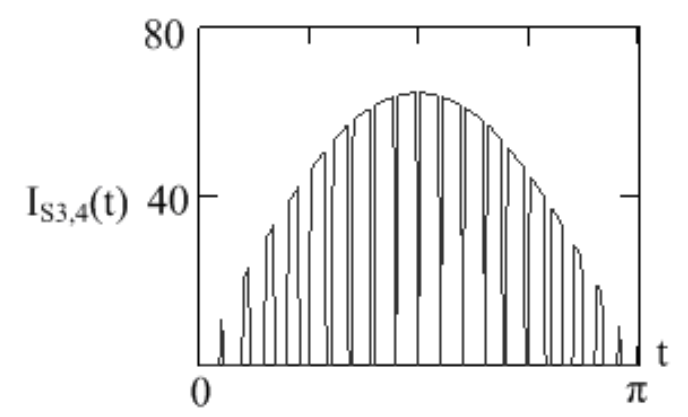

Fig. 13. Instantaneous current through switches $S_{3}$ and $S_{4}$.

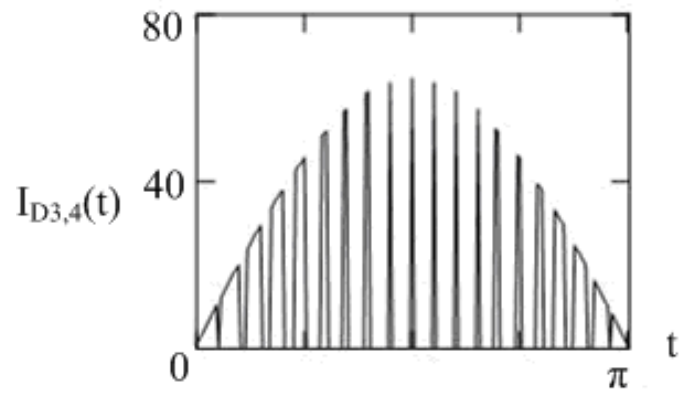

Fig. 14. Instantaneous current through diodes $\mathrm{D}_{3}$ and $\mathrm{D}_{4}$.

The current flowing through the DC bus capacitor can be obtained using (10).

$$
I_{C b_{R U S}}=\sqrt{I_{1_{R M S}}^{2}+I_{2_{R U S}}^{2}}
$$

Where:

$I_{1 \_R M S}^{2}-$ RMS value of the AC component of the input current.

$I_{2}^{2} R M S-R M S$ value of the rectifier output current.

\section{EXPERIMENTAL RESULTS}

This section presents the experimental waveforms of the proposed topology operating with nominal power and linear load of $1 \mathrm{~kW}$.

Figure 15 and 16 present, respectively, the assembled power and control prototypes.

The input voltage and current waveforms during one cycle are illustrated in Figure 17. The measured input current RMS value was $8.25 \mathrm{~A}$.

The output voltage and current are presented on Figure 18, where can be observed a small distortion in both waveforms on zero-crossing region. This occurs due to the synchronism between the commutation on the low-frequency inverter leg and the input voltage, due to the presence of inductive output filter. If the load was purely resistive, this distortion would be not identifiable. The measured current RMS value was $9.06 \mathrm{~A}$.

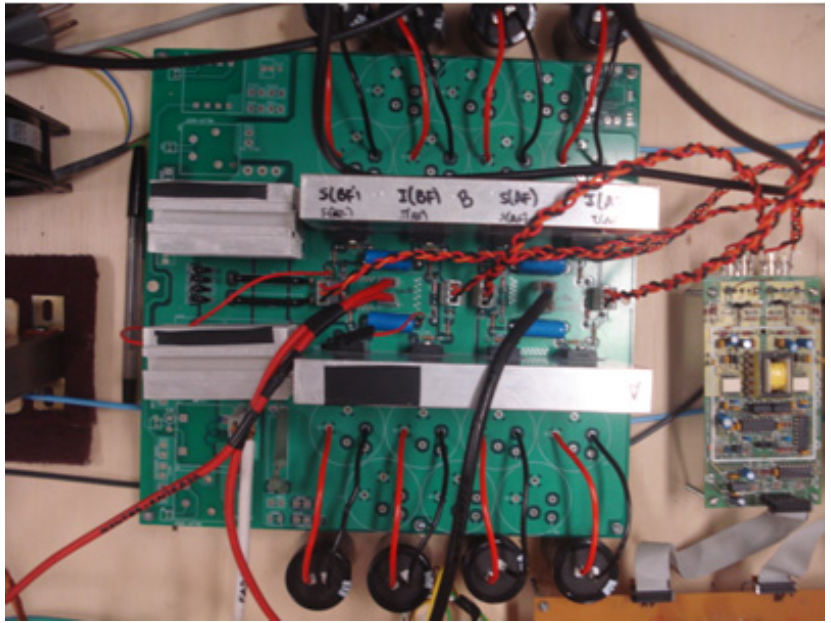

Fig. 15. Prototype power stage picture. 


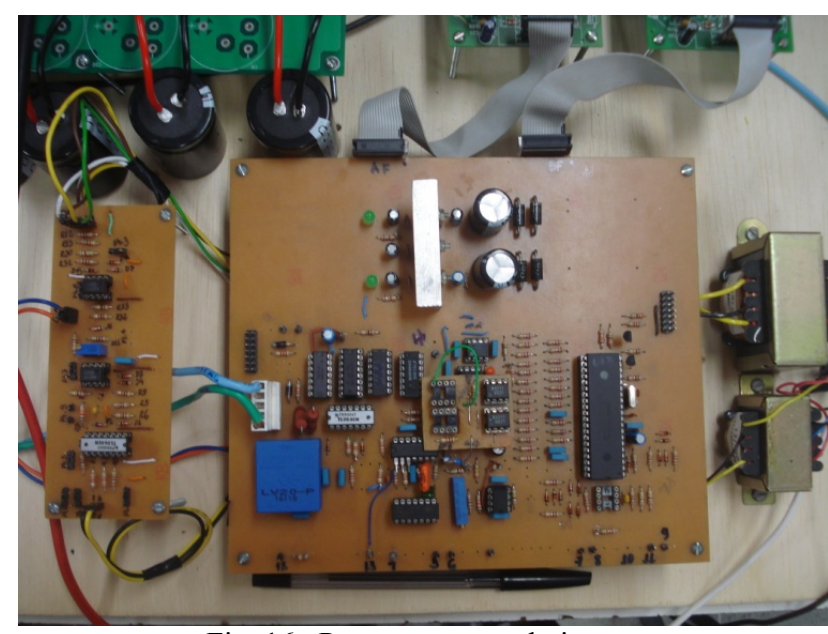

Fig. 16. Prototype control picture.

Figure 19 illustrates the current waveform through the inductor filter. The current distortion observed at the end of each semi-cycle occurs due to the reference voltage synchronism, used on the loop control of the input voltage, limiting the modulation.

Figure 20 presents the current across one of the DC bus capacitor, while Figure 21 shows the output voltage waveform before the filtering, where can be observed the three levels. Figure 22 shows the total harmonic distortion of the output voltage. Figure 23 illustrates the efficiency curve, where can be observed that the inverter efficiency, in nominal power $(1 \mathrm{~kW})$, was $91 \%$.

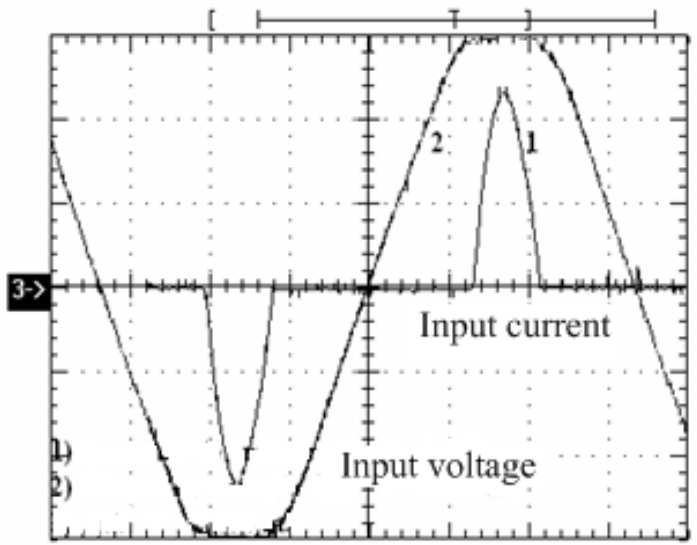

Fig. 17. Input voltage and current waveforms $(100 \mathrm{~V} / \mathrm{div}, 10 \mathrm{~A} / \mathrm{div}$,

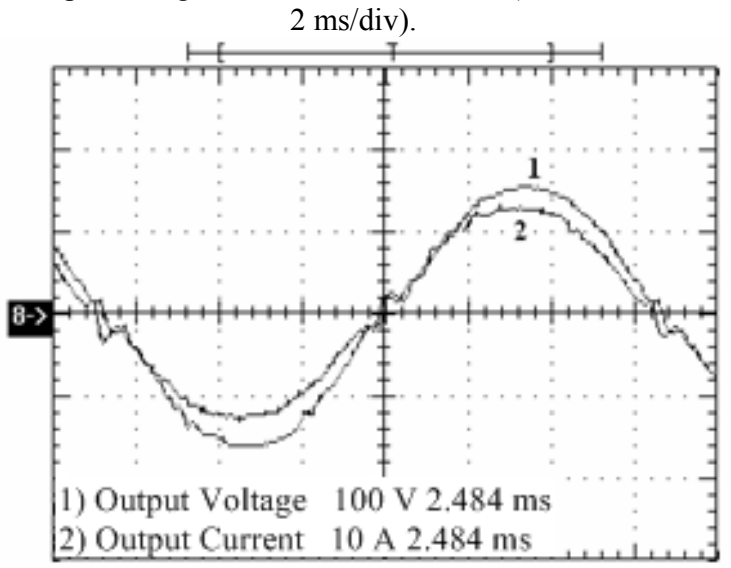

Fig. 18. Output voltage and current waveforms ( $100 \mathrm{~V} / \mathrm{div}, 10$ $\mathrm{A} / \mathrm{div}, 2 \mathrm{~ms} / \mathrm{div})$.

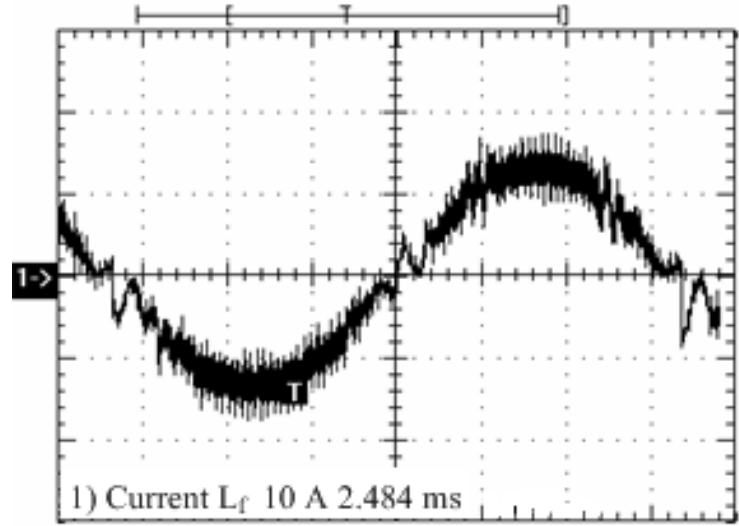

Fig. 19. Waveform of the current through the inductor filter (10 $\mathrm{A} / \mathrm{div}, 2,484 \mathrm{~ms} / \mathrm{div})$.

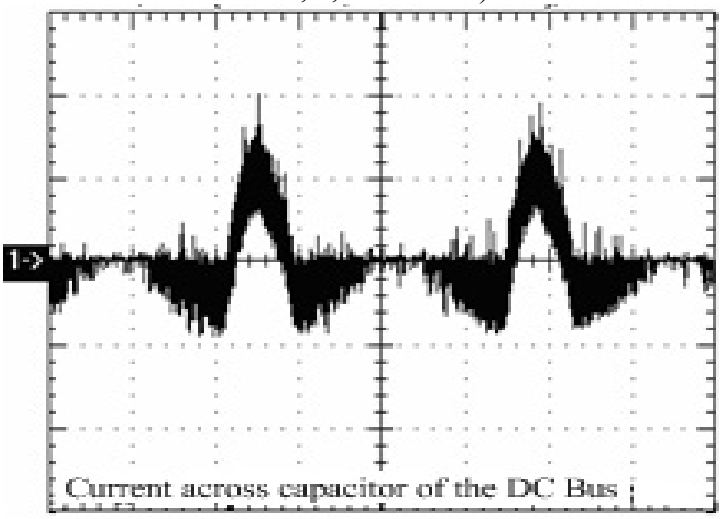

Fig. 20. DC bus current (2 A/div, $2.5 \mathrm{~ms} / \mathrm{div})$.

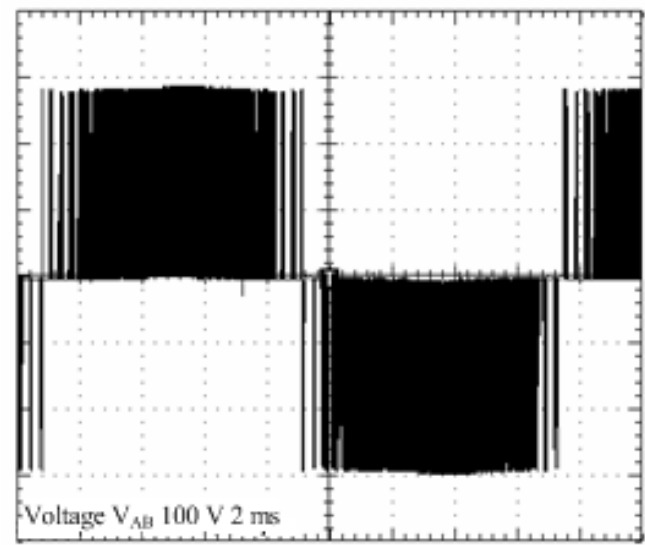

Fig. 21. Non-filtered output voltage (100 V/div, 2ms/div).

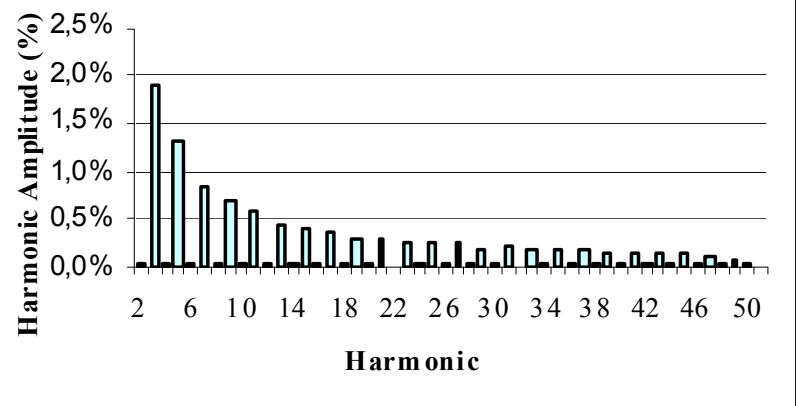

Fig. 22. Total Harmonic Distortion. 


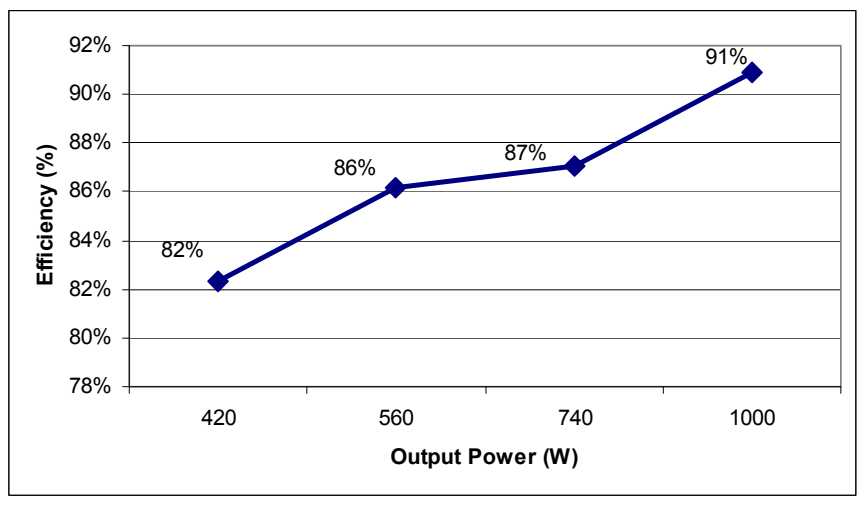

Fig. 23. Efficiency curve.

\section{CONCLUSION}

This paper presented an inverter topology which is far suitable for high power and great output voltage applications. The sinusoidal PWM modulation using the rectified sine waveform as reference was the most coherent with the necessities, as better characteristics from the waveforms were obtained.

The adopted circuit presents a fewer number of components if compared to conventional topologies, which guarantees good performance and efficiency. Also it possesses the qualities of single-pole modulation PWM three levels.

\section{ACKNOWLEDGEMENT}

To the FUNCAP that supports the technologic development of Ceará state, and to the GPEC members, for the friendship and diary support and knowledge exchange.

\section{REFERENCES}

[1] C. G. C. Branco, "A non isolated on-line UPS with universal input and output voltage", Dissertation presented at Universidade Federal do Ceará as partial of fulfillment of the requirement for the degree of Master in Electrical Engineering. Fortaleza, 2005.

[2] R. A. da Câmara, L. M. Menezes, H. A. Oliveira, C. M. T. Cruz e R. P. T. Bascopé (2007). "Voltage Preregulator Based on Three State Switching Cells For Application in UPS System”. V SNCA - National Seminary of Control and Automation, 2007.

[3] M. Ryan, W. Brumsickle and R. Lorentz, "Control Topology options for Single-Phase UPS Inverters", IEEE Transactions on industry Applications, Vol. 33n No. 2, pp. 493-501, 1997.

[4] I H. A. de Oliveira, "6 kVA Dual Conversion Uninterrupt Power Supply with output isolation.", Dissertation presented at Universidade Federal do Ceará as partial of fulfillment of the requirement for the degree of Master in Electrical Engineering. Fortaleza, 2007.

[5] I. Barbi e D.C. Martins, "Introduction to the study of converters $D C$-AC", Edition of the authors, Florianópolis, 2005.
[6] N. Mohan, T. M. Underland, e W. P. Robins, "Power Electronics: converters, applications, and design". 2 edição. New York, USA. John Wiley \& Sons, 1995.

[7] M. H. Rashid, "Power Electronics: circuits, devices and applications”, São Paulo, Makron Books, 1999.

[8] D. M. Divan, "A new topology for single phase UPS systems". In Conference Record of the Industry Applications Society, Vol. 1, Oct., 1989, pp. 932-936.

[9] L. C. Tomaselli, "Study of a variable speed electrical drive for permanent split capacitor induction singlephase motor used blowers." Thesis presented at Universidade Federal de Santa Catarina partial of fulfillment of the requirement for the degree of Doctor in Electrical Engineering. Florianópolis, 2004.

$[10]$ V. Voperian, "Simplified analysis of PWM converters using the model of the PWM switch: parts I and II". In: IEEE Transactions on Aerospace Electronic systems, v.AES-26, pp. 490-505, 1990.

[11]I. Barbi, D. C. Martins. "Electronics of Power: projects of keyed sources". Florianópolis. Edition of the authors, 2001.

[12]F. M. A. Lianrd, "Double Conversion Uninterrupted Energy System with Rectifier and Inverter Integration.", Dissertation presented at Universidade Federal do Ceará as partial of fulfillment of the requirement for the degree of Master in Electrical Engineering. Fortaleza, 2009.

[13]R. Gopinath; K. Sangsun; Jae-Hong Hahn; P. N. Enjeti; M. B. Yeary; J. W. Howze. "Development of a low cost fuel cell inverter system with DSP control". In IEEE Transactions of Power Electronics, v.19, n.5, p. 12561262, 2004.

[14]J. S. Lai; A. R. Hefner. "Emerging silicon-carbide power devices enable revolutionary changes in high voltage power conversion". In IEEE Transactions Power Electronics Society Newsletter, 2004.

[15]R. Krishman; S. Srinivasa. "Topologies for uninterruptible power supplies". In Proc. IEEE International Symposium on Industrial Electronics, Hungary, pp. 122-127, 1993.

[16]L. M. Menezes, "Inversol - Development of uninterruptible power supply to be used in a photovoltaic system." Dissertation presented at Universidade Federal do Ceará as partial of fulfillment of the requirement for the degree of Master in Electrical Engineering. Fortaleza, 2007.

[17]H. F. Gerent, "Design methodology for low THD singlephase voltage-source inveters suppying non-linear loads." Dissertation presented at Universidade Federal de Santa Catarina as partial of fulfillment of the requirement for the degree of Master in Electrical Engineering, Universidade Federal se Santa Catarina. Florianópolis, 2005.

[18]P. P. Praça, "Design, implementation and comparison among digital controllers applied to a three-level inverter". Dissertation presented at Universidade Federal do Ceará as partial of fulfillment of the requirement for the degree of Master in Electrical Engineering. Fortaleza, 2006.

[19]I. Barbi, "Power Electronics", 3a . Edition, Florianópolis, Edition of the authors, 2000. 


\section{BIOGRAPHIES}

Fabíola Maria Alexandre Linard was born in Juazeiro, Bahia, Ceará. She received the B.Sc. and M.Sc. in electrical engineering from Federal University of Ceará, Brazil, in 2002 and 2009, respectively. Currently is $\mathrm{PhD}$ candidate on power electronics in Federal University of Ceará and researcher in the Group of Power Processing and Control.

Gustavo A. L. Henn was born in Fortaleza, Ceará, Brazil, in 1983. He received the B.Sc. and M.Sc. degrees in electrical engineering from Federal University of Ceará, Brazil, in 2006 and 2008, respectively. Currently is $\mathrm{PhD}$ candidate on power electronics in Federal University of Ceará and researcher in the Group of Power Processing and Control. His interest areas include static power converters, renewable energy applications, and multilevel converters.

Cícero Marcos Tavares Cruz received the B.Sc. degree in electrical engineering from Federal University of Ceará, Brazi, in 1990, and the M.Sc. and Dr. degrees in electrical engineering from the Federal University of Santa Catarina, Santa Catarina, Brazil, in 1993 and 2002, respectively. He is currently an Adjunct Professor with the Department of Electrical Engineering, Federal University of Ceará, Ceará, Brazil. His main research interests include power supplies, power factor correction techniques and UPSs.
Rene Torrico Bascopé received the B.Sc. degree in electrical engineering from San Simón University, Cochabamba, Olivia, in 1992, and the M.Sc. and Dr. degrees in electrical engineering from the Federal University of Santa Catarina, Santa Catarina, Brazil, in 1994 and 2000, respectively. He is currently an Adjunct Professor with the Department of Electrical Engineering, Federal University of Ceará, Ceará, Brazil. His main research interests include power supplies, power factor correction techniques, UPSs, and renewable energy systems.

Dr. Torrico-Bascopé is a member of the Brazilian Power Electronics Society.

Demercil de Souza Oliveira Júnior received the B.Sc. and M.Sc. degrees in electrical engineering from the Federal University of Uberlândia, Uberlândia, Brazil, in 1999 and 2001, respectively, and the Ph.D. degree from the Federal University of Santa Catarina, Santa Catarina, Brazil, in 2004. He is currently an Adjunct Professor with the Department of Electrical Engineering, Federal University of Ceará, Ceará, Brazil. His research interests include dc-dc conversion, soft commutation, and renewable energy.

Dr. Oliveira is a member of the Brazilian Power Electronics Society. 